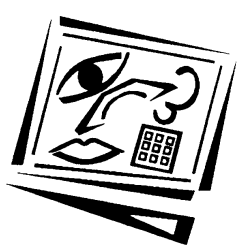

\title{
Using contemporary topics and Internet resources to stimulate student-centred learning
}

\author{
Susan E. Lee and Kyra J. Woods
} Griffith University

\begin{abstract}
In this paper we describe how we fostered learning by modifying an existing course which covered topics relevant to biosciences. This course was offered predominantly to first year undergraduate science, biomedical science and environment students. The students were trained to find reliable scientific information via computer searches, and shown ways to use and cite references. Small teams of students used Internet resources to find, evaluate and summarise information for 15 minute PowerPoint presentations. An initial lack of confidence in presentation ability improved significantly over this period. The students identified the computer workshop format, the presentations and the interesting lectures as outstanding course features. The structure facilitated student-centred learning by providing interdisciplinary research topics that were considered interesting, relevant and authentic. The learning environment supported the diversity of abilities and interests of the students. Other positive student outcomes were the formation of friendships, a broadened interest in science, discovery of possible career paths, and greater confidence in their ability to find good references. The provision of computers with Internet access in the students' workshops changed the previously tutor-led approach to a student-centred format, ideal for ensuring active learning. The choice of interesting, multidisciplinary topics and lecturers also helped mitigate the possible negative effect of a student cohort drawn from diverse disciplines.
\end{abstract}

\section{Introduction}

Over the past two decades there has been an increased emphasis on student-centred learning, facilitated by good direction from the teacher. For teaching in university science courses, many strategies have been devised to facilitate this approach. This has been done in a range of fields including ecology, statistics, chemistry, molecular biology and biological sciences (McLoughlin \& Taji, 2005). For example, some successful strategies incorporated computer assisted learning programs or online assessment and feedback. Others employed problem based approaches and used strategies such as peer mentoring. The common thread is that the strategies aim to encourage a deep approach to learning, brought about by a shift in student motivation towards a natural desire to satisfy their own curiosity.

Although many university courses have not taken advantage of it, the increasing familiarity of students with many forms of information technology devices in everyday life and their improved computer literacy should facilitate greater use of these technologies in teaching. Obvious advantages of the use of computers include ease of accessing vast arrays of data, images, sound and text. In addition there is the opportunity to encourage students to find, analyse, synthesise and evaluate information. Such use can replace passive acceptance of information from a lecturer 
and instead encourage students to engage more actively with their courses. This involvement in active learning is in contrast to the information conveyed in traditional lectures where the lecturer has already done the processing and packaging for the students. Use of computers can also enhance collaborative learning because of the ease with which files and web addresses can be shared. For example use of Blackboard's Discussion Boards and Group Pages allows students (and teachers) to readily exchange emails, upload files and post questions and answers.

Various strategies are known to help people to learn. Questions that are perceived as real and relevant encourage acquisition of new information. Having some control over what they are learning and having the chance to explain, discuss and reflect on new ideas also promote learning (Dearn, 1997). In this paper we describe how we modified an existing course, offered to predominantly first year undergraduate science, biomedical science and environment students, to foster learning. This was achieved through setting tasks that required the use of computers to find information, interaction with others to master knowledge, and collaborative work in a small group to assemble and present that information using PowerPoint slides. We also selected lecture and workshop topics with relevance to both biomedical and environmental science students and chose lecturers able to integrate disciplines and speak with authority and enthusiasm.

\section{Background to the course and the student cohort}

The course, Topics in Biosciences, was originally offered primarily to first year undergraduate biomedical science students and aimed to excite and inform students about contemporary issues in biosciences. The semester-long, 10 credit point course had a fairly traditional format, with 21 hours of lectures and nine 2 hour workshops in which the tutors were responsible for stimulating discussion and participation. Some lectures covered study skills, use of library resources and referencing techniques, but there were no workshops specifically aimed at practising these skills. The remainder of the lectures had a human biology bias and the workshop discussion topics were aligned with the lecture coverage. Assessment was through workshop quizzes, a multiple choice exam, an essay and the presentation of a 10 minute seminar at the end of the semester by every student.

\section{Challenges associated with the student cohort}

In 2009 enrolments for Topics in Biosciences included students of Ecology and Conservation Biology $(34 \%)$, Biomedical Science $(46 \%)$, and other science and environment majors (20\%). A major challenge was to satisfy the student diversity by choosing topics that were contemporary, interesting and relevant. We also wanted the course to enhance generic skills, in particular, the capacity to find and use accurate scientific information, oral communication, and teamwork in which students from different disciplines worked collaboratively to answer questions that required multidisciplinary knowledge.

The student enrolment numbered 110 (81 first year, 20 second year and 9 third year undergraduates). They had varied educational backgrounds. Some second and third year students with considerable theoretical background chose the course as an elective. First year mid-year entry students had done no biology at university level, in contrast to other first year students who had completed first semester courses in human and cell biology. Some international and mature-age students were not familiar with 
computer applications, such as PowerPoint, and had not used computer databases and other library resources. This diversity of prior experience was another challenge for the course design.

\section{Methodology}

\section{Lectures}

The initial lectures in the course covered general background information that would be needed throughout the semester. The Science Librarian demonstrated use of the database Scopus, which covers many journals of relevance to both biomedical and environmental topics. This included an example of the use of a Scopus option that allows rapid production of a bibliography for downloading into a document. He also showed how web sites such as Google and Wikipedia can produce reliable information or lead to other reliable Internet sites. Specific examples from course topics were used to illustrate the variety of sites that could provide information and how to change search parameters to target the most relevant and reliable sources.

In preparation for their own presentations, the students participated in an interactive lecture devoted to identifying desirable and undesirable attributes of presentations in general. At the end of this lecture, students submitted a survey identifying what they considered good and bad features of a presentation. From this, the course convenor compiled a set of best practice guidelines for the students to use for their own presentations.

Finally, in the expectation that many of the topics to be covered would have social and ethical dimensions, two lectures on bioethics were part of this background training. The remainder of the lectures were grouped under three overarching themes, each with elements related to both health/disease and ecology, where understanding required information from both perspectives (Table 1).

Table 1: Themes used in the lecture series for the course Topics in Biosciences

\begin{tabular}{|c|c|}
\hline Overarching themes & Lecture topics \\
\hline \multirow{4}{*}{$\begin{array}{l}\text { Utilisation and } \\
\text { conservation of } \\
\text { natural resources }\end{array}$} & $\begin{array}{l}\text { Molecular farming and uses for genetically modified plants (e.g. antibody } \\
\text { production) }\end{array}$ \\
\hline & Tissue engineering using natural products \\
\hline & Utilising the medicinal properties and food value of Australian plants \\
\hline & $\begin{array}{l}\text { Conserving the world's genetic resources: "Sowing for apocalypse" and } \\
\text { the global food crisis }\end{array}$ \\
\hline \multirow[t]{4}{*}{ Disease ecology } & $\begin{array}{l}\text { Dengue fever; Medical aspects and applying knowledge of ecology to help } \\
\text { to control it }\end{array}$ \\
\hline & Parasites: Disease and ecology (epidemiology) \\
\hline & $\begin{array}{l}\text { Mouth microbial ecology; Biofilms, kissing and dental decay, ecological } \\
\text { pressures, Coca-Cola }\end{array}$ \\
\hline & $\begin{array}{l}\text { Tasmanian devil facial tumour disease: Lessons in disease and } \\
\text { conservation biology }\end{array}$ \\
\hline \multirow[t]{2}{*}{$\begin{array}{l}\text { Investigation of } \\
\text { bioresources }\end{array}$} & $\begin{array}{l}\text { DNA barcoding: Use of ancient DNA to trace historical events (e.g. bird } \\
\text { feather DNA from Maori cloaks to track trading routes) }\end{array}$ \\
\hline & $\begin{array}{l}\text { Forensic techniques including odontology; their use in natural and other } \\
\text { disasters (Thailand tsunami; helicopter and plane crashes) }\end{array}$ \\
\hline
\end{tabular}


Presentation of this material was from both in house and invited guest lecturers, known for their passion for their topics. Each lecturer issued the students with 3-4 short questions that were to be answered during the lecture. This served several purposes: it highlighted points considered important by the lecturer; it helped keep the students alert and focused on the topic; it served as a roll call for attendance, which counted towards the students' final mark (20\%); and it provided relevant questions for the final exam.

\section{Workshops}

Workshops were held in rooms with computers to allow Internet access and use of library databases that permitted access to full journal articles. Each workshop group had 20-24 students in it, from a mix of study programs. The workshop topics, which matched the overarching themes, had an Australian context bias. The initial general workshops put into practice some of the themes from the early lectures. Students worked individually to answer short questions by applying principles of scientific information retrieval, and citing of references. Some questions required understanding of bioethics. Others required the students to use PowerPoint to make some short summary slides of a topic of their choice. The experienced students completed this work quickly, freeing time for the tutor to concentrate on helping those with less prior experience. Students also assisted each other during these sessions, by sharing useful web sites or demonstrating to others how to manipulate options in PowerPoint.

The students then began a series of workshop sessions where they were responsible, as members of a small team, for researching then presenting material. The topics given to these teams were chosen for their interest and multidisciplinarity (Table 2). We sought suitable topics from many sources, including science sites on ABC radio and television (e.g. Catalyst, The Science Show, Landline), CSIRO and Primary Industry sites, journals such as New Scientist, and newspapers. We also drew on informal discussions with many colleagues, some of whom contributed to the lecture series or whose research incorporated the multidisciplinarity that we were seeking.

Table 2: Examples of contemporary workshop topics used in the course, Topics in Biosciences. Small teams of students had to use primarily electronic resources to research an allocated topic and then present their findings to the larger workshop group a week later.

Overarching themes $\quad$ Examples of associated workshop topics

\begin{tabular}{|l|l|}
\hline \multicolumn{1}{|c|}{ Overarching themes } \\
$\begin{array}{l}\text { Utilisation and conservation } \\
\text { of natural resources }\end{array}$ & $\begin{array}{l}\text { Resilin; Frog "Glue"; Introduced carp in Australia; Plants for life; } \\
\text { Green fluorescent protein from jellyfish }\end{array}$ \\
\hline Disease ecology & $\begin{array}{l}\text { Hendra virus and bats; Bluetongue virus and climate change; Frog } \\
\text { chytridial disease; Komodo dragon conservation, pathogenic } \\
\text { bacteria and venom; Coextinction }\end{array}$ \\
\hline $\begin{array}{l}\text { Investigation of } \\
\text { bioresources }\end{array}$ & $\begin{array}{l}\text { DNA barcoding; Palynology - pollen in ecology, pollen in forensic } \\
\text { science; Detecting potentially dangerous live imports and illegal } \\
\text { trade in wildlife; Detecting different species - DNA, sounds, } \\
\text { tracks, scats; Insects and the law. }\end{array}$ \\
\hline
\end{tabular}

The workshop topics supplied to the students had a single main theme, as indicated by the list in Table 2, but we also provided some guidance with five related questions. The emphasis of these questions indirectly provided logical subheadings for a wellconstructed talk. To help the students get started on productive searches for information we also provided examples of useful web sites (Table 3). 
Table 3: An example of a workshop topic for the course, Topics in Biosciences. Some guidance, designed to help with logical construction of a presentation, was given to the student teams in the form of sub-questions.

\begin{tabular}{|l|l|}
\hline $\begin{array}{l}\text { Theme 1: } \\
\text { Group topic: }\end{array}$ & $\begin{array}{l}\text { Utilisation and conservation of natural resources } \\
\text { Green fluorescent protein }\end{array}$ \\
\hline Question 1 & What is GFP? Which organism was GFP isolated from and in what year? \\
\hline Question 2 & $\begin{array}{l}\text { Describe two (2) features of GFP that make it such a useful tool for studying } \\
\text { cellular and developmental processes. }\end{array}$ \\
\hline Question 3 & \begin{tabular}{l} 
Describe a scientific technique which utilises GFP. \\
\hline Question 4 \\
Since the discovery of GFP, scientists have 'made' other fluorescent proteins \\
by mutating the sequence of GFP. Why is it useful to have a 'toolbox' of \\
different fluorescent proteins?
\end{tabular} \\
\hline Question 5 & What is 'brainbow'? Include a picture if possible. \\
\hline $\begin{array}{l}\text { Getting started: } \\
\text { Useful websites } \\
\text { and databases }\end{array}$ & $\begin{array}{l}\text { Scopus database search } \\
\text { http:// / en.wikipedia.org/wiki/Main_Page } \\
\text { http://nobelprize.org/nobel_prizes/chemistry / laureates / 2008/press.html } \\
\text { http:// /images.google.com.au/imghp?hl=en\&tab=wi }\end{array}$ \\
\hline
\end{tabular}

The allocated teams of 4-5 students per research topic had a mix of gender and student study programs. The students were required to give a presentation for each of the three overarching themes, with the team allocations changing each time. In the first 2 hour workshop for each of the three allocated topics the students met their team members, examined aspects of their research topic and agreed on subdivision of tasks. Under the general guidance of the tutor, they then used the Internet resources to retrieve information, discuss it with their team members, and work towards producing a PowerPoint presentation ( 15 minutes) for the following week. After each presentation there was about 5 minutes for questions from the student audience and tutor. All the PowerPoint presentations were uploaded to the course Blackboard web site. This provided a revision resource and allowed teams to see how groups in other workshops had approached the same topics.

\section{Assessment}

Lecture attendance was worth $20 \%$, three presentations were worth $60 \%$, and a final exam was worth $20 \%$. The final exam questions were all short answers, based on lecture content and workshop topics. They emphasised application of knowledge where possible rather than rote learning. For example, a question related to frog "glue" was:

The substance secreted by the frog Notaden bennetti has found applications in surgery.

What are four properties of this "glue" that match many of the requirements for substances used in tissue engineering?

This question required the students to revise features of substances used in tissue engineering, and assess the suitability of the frog secretion accordingly. The students were given 85 possible exam questions a fortnight ahead for revision, and the exam included about 40 of these, from which they had to choose to answer 20 (5 each from 4 subsections of the paper). This choice helped allow for the diversity of interests within the student cohort.

\section{Evaluating outcomes}

The students were given surveys to be completed anonymously after the final exam in late October 2009. Opinions on the good or poor features of the course, and ideas for 
future topics, were sought using open questions. Closed questions examined the students' familiarity with scientific articles and finding good quality references (before and after the course). These questions sought views on the relevance and interest of topics, changes in confidence to give oral presentations, and various other outcomes of the course including whether the course facilitated formation of new acquaintances, heightened their interest in science or revealed unexpected career pathways. The responses were on a 5-point Likert rating scale. The results were analysed using Minitab statistical software, employing tests suited to non-parametric data. Single response answers were tested using the Wilcoxon single-sample signed rank test. Comparisons of attitude before the course started and after its completion were tested using the Mann-Whitney test of two population medians.

\section{Results}

\section{Accessing, reading and referencing current scientific articles}

In the Topics in Biosciences course students used computers to access recent scientific journal articles and summarise current scientific information on their workshop topics. Prior to enrolling in this course, the majority of the class had rarely read scientific articles (median value of 2 ; significantly lower than average median of $3, P<0.0001$ ) (Figure 1).

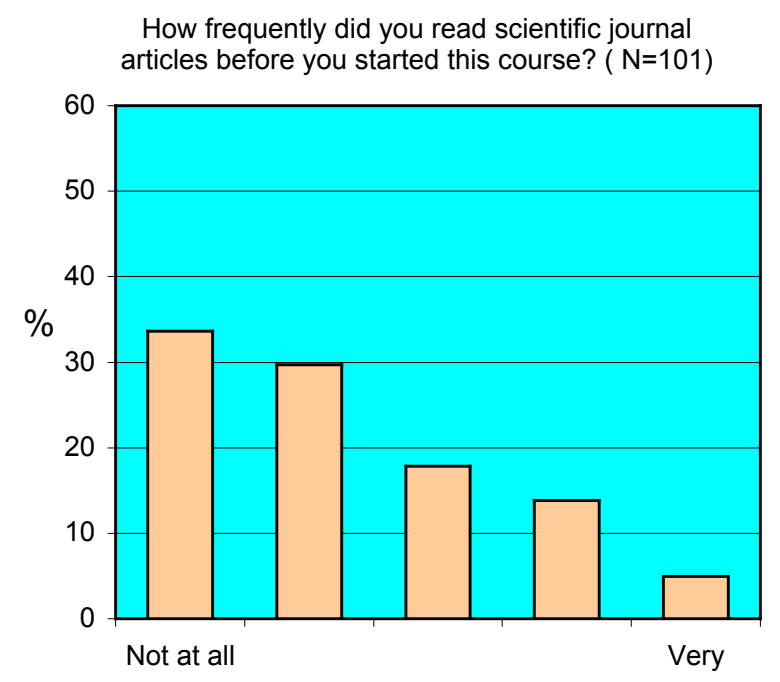

Figure 1: Results of student surveys assessing how frequently students read scientific journal articles before undertaking the course Topics in Biosciences. Five point Likert scale, responses from "not at all" through to "very".

Some students however, considered themselves very capable of finding good reference articles before the course started (Figure 2). Upon completion of the course, the ability of the majority of students to find good references was significantly enhanced (Figure 2) (median of 4 for "after" significantly higher than "before" median of $3, P<0.00001$ ). 


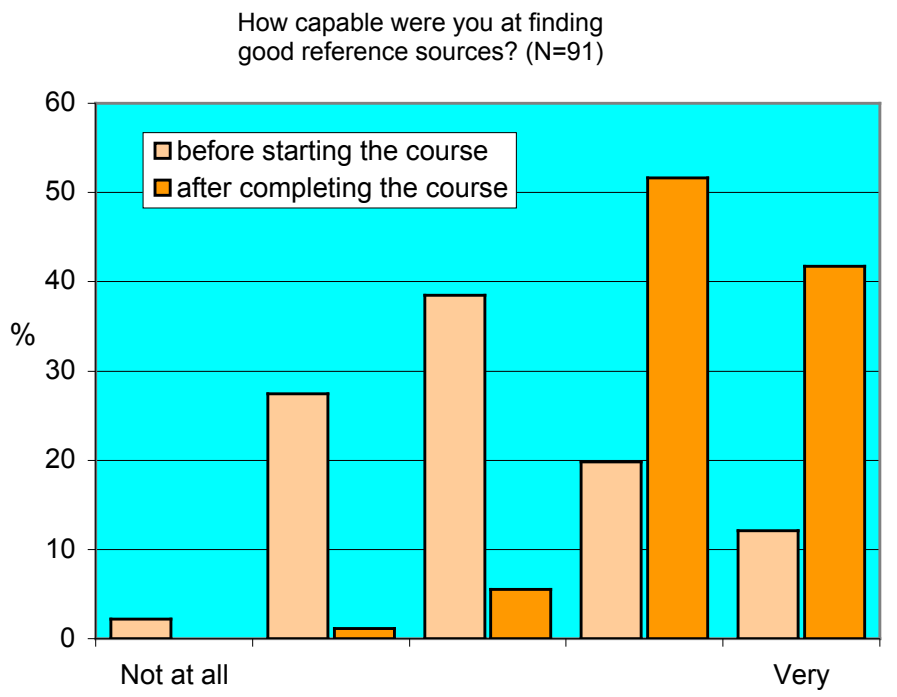

Figure 2: Results of student surveys assessing how capable the students considered themselves to be at finding good reference sources. Five point Likert scale, responses from "not at all" through to "very".

\section{Interest and relevance of course contents}

A challenge associated with presenting a course to biomedical and environmental science students was to find topics that were interesting and relevant to both disciplines. Figures 3 and 4 demonstrate that these objectives were met by both the lecture and workshop topics. The median value for topic interest was 4 , significantly higher than the average median value of $3(P<0.0001)$. The relevance of lectures and workshops was slightly lower, with a median value of 3.5, significantly higher than the average median value of $3(P<0.0001)$. For the questions relating to relevance, $5 \%$ of the students indicated that they were not sure of the relevance of both the lecture and workshop series.

\section{Oral communication skills and teamwork}

The inclusion of three team presentations in the course aimed to enhance the students' generic skills of teamwork and capacity to give good oral presentations. The student responses showed a significant improvement in confidence at public speaking after completing the Topics in Biosciences course (Figure 5), with median value of 4 after completing the course $(\mathrm{N}=105)$, significantly higher than the median value before starting the course of $3(P<0.0001)(\mathrm{N}=103)$ (Lee \& Woods, 2010).

The value of working in a team was identified in the open questions. Some typical comments were:

Group assignments - provide teamwork and help students to meet many others in the course.

The workshop: working together with other students not only helped us to meet new people, but was a very effective way of learning material. 


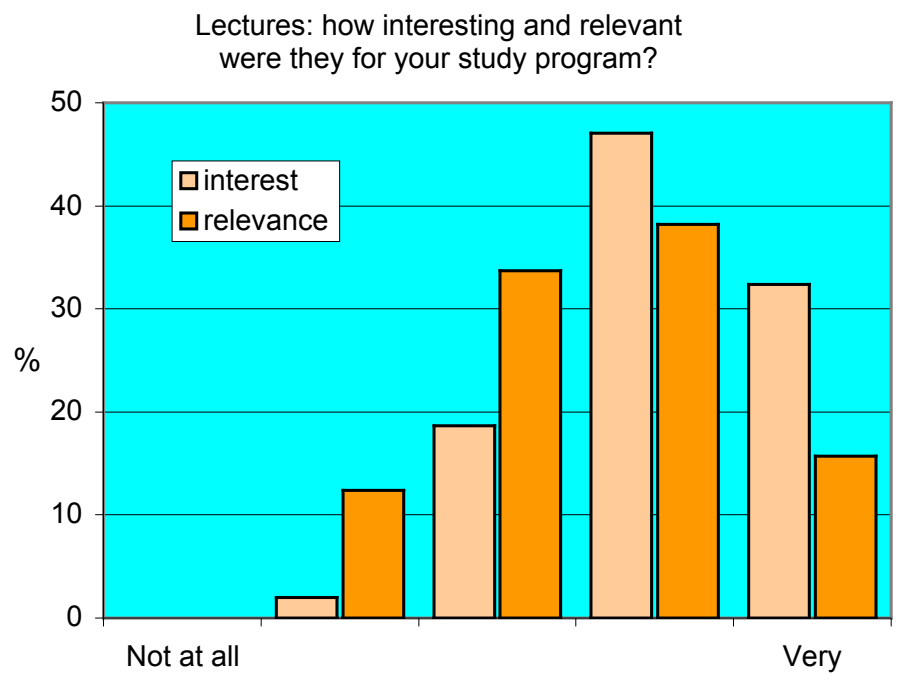

Figure 3: Students' views on the interest $(\mathrm{N}=102)$ and relevance $(\mathrm{N}=89)$ of topics covered in the lectures in the course Topics in Biosciences. Five point Likert rating scale.

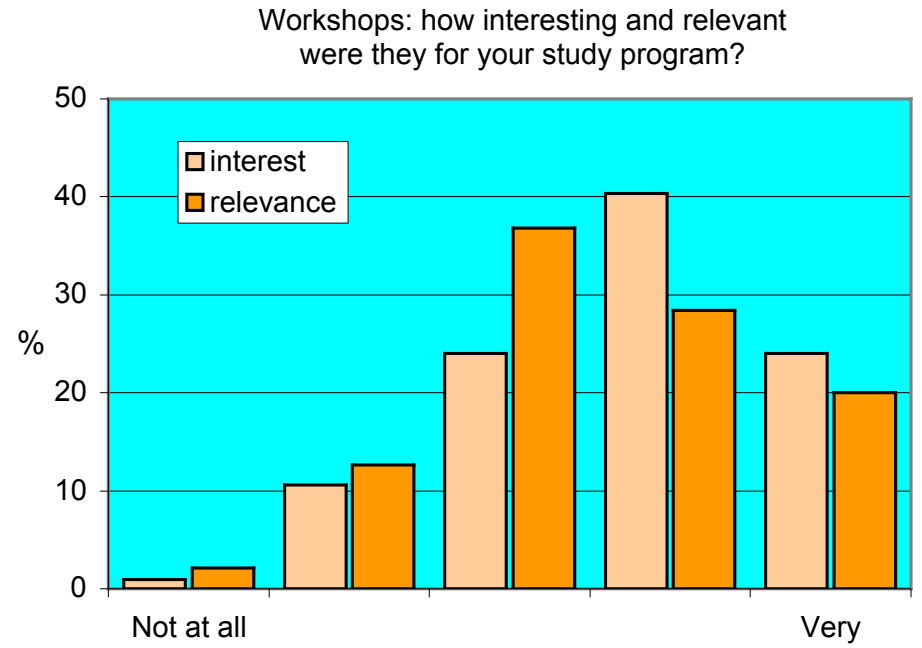

Figure 4: Students' views on the interest $(\mathrm{N}=104)$ and relevance $(\mathrm{N}=95)$ of topics covered in the workshops, in the course Topics in Biosciences. Five point Likert rating scale.

\section{Other course attributes}

For each of the following statements, median values were significantly higher $(P<0.0001)$ than the average median value of 3 for a 5 point Likert rating scale $(1=$ strongly disagree through to $5=$ strongly agree): 
- The content of this course has increased and broadened my interest in science

- The content of this course has revealed some possible career paths

- I found this course challenging but not excessively difficult

- The learning environment was supportive of diversity of abilities and interests

- We had opportunities to learn through discussion with one another and with the lecturer

- The way that the workshops were organised helped me to make new acquaintances

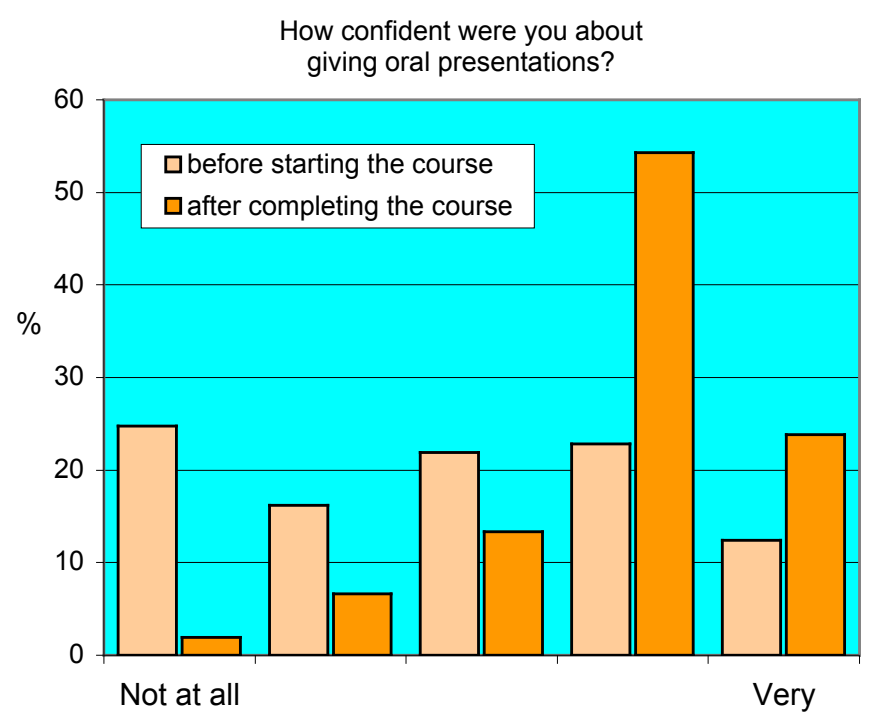

Figure 5: Student assessment of their confidence to give oral presentations before $(\mathrm{N}=103)$ and after $(\mathrm{N}=105)$ the course Topics in Biosciences. Five point Likert rating scale.

Spontaneous student responses also highlighted the value of the workshop structure for facilitating new friendships. The student cohort as a whole thought that the existing content was good, with only $6.5 \%$ of the class suggesting removal of some of the material that related to food and plants.

The students contributed numerous positive comments on the course, and the value of the workshops was highlighted by many:

The way the teaching was done by having guest lecturers was great and then having to do our own research and talks were a great way to learn.

Lectures and workshops are brilliant.

Interesting and widespread material.

The workshops were good for each theme we had to do, most of the topics are relevant for my course, the guest lecturers were excellent, this was my favourite class. Even though I still suck at them the presentations have helped big time with speeches. 


\section{Discussion}

The lecture and workshop themes, and format, for the course Topics in Biosciences, resulted in very positive responses from the students and the tutors. One tutor, involved with the course in previous years, immediately noticed and commented on the change in student attitude. Previously many students came unwillingly to tutorials, often motivated by the need to gain marks for attendance, and then barely participated in discussions. In the new format she found that students came willingly. They immediately settled into searching for information on the computers, shared information with each other, sought guidance as needed, and often had to be encouraged out of the room at the end of the two hour session because they had become interested in their research topics. Their capacity to work independently allowed her to concentrate on helping those with less prior experience.

At the beginning of the course the majority of students indicated that they did not access scientific journal articles at all or only rarely (Figure 1). However, around 19 students indicated much more frequent access to journal articles. This difference probably reflects the presence of second and third year students in this course (29 of 110 students) and their use of journal articles in other courses. The more experienced students in this class might have been expected to find this first year level course too basic but there is no indication from either the open or closed questions that this was the case. Their presence proved invaluable in the collaborative teamwork tasks. The more senior students could explain some of the biology to those with less theoretical backgrounds, a practice that enhances the learning of both the teacher and the learner. Also for the experienced students, many topics allowed them to see applications for their theoretical knowledge, that is, they were able to build on their current knowledge and appreciate its wider relevance. Some of the comments from these students included:

The workshops; working together with other students not only helped us to meet new people, but was a very effective way of learning material. (3rd year BSc (Microbiology major))

For me, presentation is good because as I know in my degree program I may have a lot of chances to write reports. But this is the only subject I ever had to do a presentation ... I learnt lots of stuff from doing them (2nd year biomedical science student)

I really enjoyed group presentations (4th year B Inf.Tech/BSc)

I like the format of 3 presentations (2nd year BSc (Ecology and Conservation Biology))

Newer students also enjoyed the acquisition of knowledge:

Interesting lecturers were great and helped me remember topics based on interest.

Overall a very rewarding course as I learnt a lot and every topic was interesting.

The positive shift in both the ability to find good references (Figure 2) and the confidence at giving oral presentations (Figure 5) indicates that the course was able to provide good learning outcomes for the majority of students, irrespective of their background training. The active learning that came from giving presentations was acknowledged by the students with more than $57 \%$ of respondents believing that retention of three presentations was superior to substitution of one talk with a written report. 
Various attributes of the workshops and presentations were singled out for comment by many students:

Lectures and workshops are brilliant.

I thoroughly enjoyed the presentations.

The speeches assessment. Researching a lot makes your learn heaps.

Doing presentations was a good idea, help to be more confident.

The presentations in groups:

- get to know people in the course

- learn about different topics that are interesting

- confidence building

Even at first year level, students are able to appreciate the need to gain not only specific knowledge but also generic skills. As one student commented:

I think the presentations are very important in providing students the skills and the confidence to present material to their peers - a skill required in all science pathways.

Only 15 students made suggestions in response to a survey question asking the students to identify any aspects of the course that needed improvement. Of these, two related to the workshops. One commented on a disadvantage of group work:

While assessing speeches as a group relates to how well we can work together, too much emphasis was placed on this and in the case of a group member which brought down the whole group, this felt very unfair. Perhaps give an assessment item which also assesses the individual.

Another student highlighted the timetabling difficulties:

Workshops. It was too hard to find time to meet with the BPS students when our ENV classes clashed with theirs.

Student enjoyment of workshops, working in groups and giving presentations were also features of problem based learning modules implemented in the University of Western Australia (Pepper, 2009). However, while working in groups was rated as enjoyable by $62 \%$ of their student groups, $14 \%$ of students did not enjoy group work or commented on group issues. Difficulty in meeting out of class time is a common theme, although the use of email and file upload options provided by Blackboard probably minimised that problem for the Topics in Biosciences course. Only one student commented on this challenge. The approval of the workshop and presentation structure in Topics in Biosciences may reflect that the course was entirely redesigned to effectively integrate these elements throughout the course, whereas the problem based learning modules at the University of Western Australia were incorporated as relatively small components into existing courses.

It is skills such as public speaking, along with written communication, ability to manage others and effective team leadership that have been identified by former students as essential to future careers (Zekeri, 2004) The structure of the Topics in Biosciences workshops aimed to provide initial training of the students in several of these attributes and the students' comments confirm that we were largely successful in those aims. 
The allocation of students to three different research teams fostered formation of friendships both within and between the disciplines of biomedical and environmental science. Both disciplines were able to contribute information or explanations during preparation for their team presentations. Other authors who have studied interdisciplinary team teaching and student team presentations (Oitzinger \& Kallgren, 2004) found that the active learning associated with student presentations deepened and enriched the students' grasp of content. However, the authors felt that successful integration of disciplines was more likely to occur if faculty members were themselves skilful at integrating disciplines. The evident success of Topics in Biosciences themes (Figure 3) may reflect that the tutors and lecturers, although sometimes specialists, were made aware of the audience diversity and had attitudes and training that facilitated the integration of both health and environmental issues into their teaching.

For example, the lecturer who talked on the microbial ecology of the mouth is a professor of dentistry, but had also worked in agriculture where microbial biofilms are essential for plant life and are sensitive to changes in their environment. He was able to draw analogies between biofilms in many environments and talk meaningfully about the effects of environmental changes. He was also able to talk about topics dear to the average student's heart, such as the downsides of drinking Coca-Cola and the ethics of advertising! The course convenor (author SL), who initiated the changes for 2009, also approached this course from both an environmental and biomedical background, having trained in both fields. She also chose tutors with a willingness to extend their knowledge beyond their traditional, discipline-specific training.

It can be challenging to find ways to reduce the students' tendency to compartmentalise knowledge and fail to make connections between courses. Our multidisciplinary approach helped some students to appreciate the breadth of science ("Gained valuable insight into the variety of fields of study within science") and may have enhanced their critical thinking. Oitzinger and Kallgren (2004) cite evidence that integration of ideas across disciplines can enhance critical thinking, compared to outcomes when students study the same material but in different courses. Our surveys revealed that the majority of students found that the course content had helped them to discover other applications in science, had revealed some possible career paths and had increased and broadened their interest in science. The students also frequently cited the range and expertise of the lecturers, and the topics covered, as amongst the best features of the course. For example:

Overall a very rewarding course as I learnt a lot and every topic was interesting.

Overall thought this course was really good. It informed me on aspects in biosciences that I never thought of.

Guest lecturers were a good example of diversity of sciences.

Guest lecturer and topics discussed were very interesting and topical.

The wide variety of lectures, and doctors coming in, was good and kept interest.

It was pleasing to see such a positive response to the succession of different lecturers and variety of workshop topics, as such a scheme can produce lack of cohesion and unclear focus (features of the course commented on by the students in its previous iterations). Aware of this potential, we grouped lectures under the three overarching themes and further aligned the workshop topics with these themes to keep the students aware of the general focus. Further emphasis on the interrelatedness of 
various topics, both in the lecture series and in the workshops, was given in a final summary lecture by the course convenor, to highlight not just important points but to show how some themes recurred.

It is not uncommon for students to opt out of lecture attendance now that lecture summaries are often uploaded onto web sites where the students can readily access them and they can use textbooks or web sites to supplement information. Most university students undertake considerable hours of part time work, and choose to work if attendance at university is not compulsory. However in a course dealing with current issues in biosciences, textbooks on the topics are not available, and we believed that one of the ways to stimulate and broaden student interest in their science courses was to expose them to exciting lectures from enthusiastic experts.

We encouraged attendance at lectures in several ways. The two one-hour lecture timeslots were timetabled one after the other on a Monday afternoon, so that students considered it worthwhile to come to University on that day, or to stay after morning classes finished. The double time slot allowed some busy guest lecturers to make use of both sessions and meant they had only to come to the University for a single afternoon. We also encouraged attendance by allocating $20 \%$ of the students' final marks to lecture attendance, and provided short questions at each lecture to be completed during the talk and handed in at the end of the lecture. Spontaneous written comments from the students at the end of the course suggest that these strategies were successful. For example, one student said:

It was an excellent class. It is set out really well, I like that the Monday lecture isn't split up over a few days like some of my other classes

Amongst lists of good features of the course, several others highlighted liking marks being given for lecture attendance:

The use of different lecturers with a wide range of topics and the fact that you receive marks for attending lectures.

The attendance record in lectures was good because it pushed us to actually go.

A few students asked that PowerPoint summaries from all lectures be made available (not all the guest lecturers provided a copy of their talk): “... sometimes you are too busy just soaking in the information that you don't take extensive notes". The need for some backup was particularly important for some of the international students, who struggled to keep up with the lecturer and take meaningful notes. This is something that will be addressed in future course offerings, although we do not want to encourage lack of attendance by supplying too much material ahead of time. As one of the students noted, being forced to attend the lectures was good because they were so interesting and informative.

Initially a small number of students enrolled in Topics in Biosciences indicated lack of familiarity with computers and associated applications such as PowerPoint. This is in line with findings for first year biological science students at other Australian universities (Peat, Franklin, Lewis \& Sims, 2002). At the University of Sydney, many online resources are available as adjunct learning tools for first year biology students. These resources have the advantage of being accessible at all times. They were developed partly in response to the growing trend for students to spend less time on campus and more time in casual paid employment. However there was a significant 
student percentage (up to 20\%) that did not use the materials whilst others who used the materials did not rate them as particularly useful. In contrast, no adverse comments on the use of electronic resources and computer programs were received from the students in Topics in Biosciences (102 respondents from an enrolment of 110 students). The only technical hitch that created problems was a period when the student email system failed for over four days. This reduced the capacity for student communication but also stimulated the adoption of an alternative strategy to use the functioning "Upload Files" capacity within the students' Blackboard Group Pages, instead of relying on emails.

The acceptance of the use of information technology by these students might be because they had access to university computers and guidance from the tutor during the formal workshop sessions. However, no groups finalised their work during the initial 2 hour preparation period and must have used electronic resources outside that allocated time period. In this course, poor access to computers, unfamiliarity with information technology or a dislike of using computers, which contributed to lack of use of the University of Sydney online resources, did not seem to affect our students' participation. Use of the University of Sydney online resources was not compulsory whereas it was a clearly stated in Topics in Biosciences that students would use electronic resources to find the majority of the information on each research topic, and that they were required, in small teams, to prepare three presentations using PowerPoint.

The use of electronic resources was absolutely integral to the curriculum and to the assessment. The evident success of these strategies supports the notion that students are willing to use online resources, "if they are effectively integrated into the curriculum and relevant to the assessment strategies" (Peat et al., 2002; p.271). Others have pointed out that access to computers and the Internet is not sufficient - students also need the requisite skills to use them effectively (Lim \& Lee, 2000). In our course, basic training in firstly accessing and using electronic resources, and secondly, in use of relevant computer applications, was provided early in the semester, and further hints and guidance were given as needed, as the course progressed. In this supportive learning environment, the use of information technology seems to have been wholeheartedly embraced.

As would be expected for any newly revised course, there were some areas that need to be improved. The students correctly identified some inconsistencies in the way that their talks were assessed. The team presentation as a whole was given a mark for the quality of references used, but some students resented that their own exceptional effort was hidden by the listing of all references as a single block at the end of their presentation. The need to present five different research topics in a 110 minute period left little time for immediate feedback to the students on the good features of their talk and on features that could be improved. This problem could be overcome by increasing the number of workshops and reducing the workshop class sizes down to a maximum of 16-20 students, so that only four research topics would be needed. This increase in workshop repeats does however have extra cost implications. Some problem with individuals not contributing fairly to group work was not unexpected but the impact on any one group was reduced as far as possible by allocating students to new teams for each presentation. This also enhanced the chances for students to make new acquaintances. 
To achieve good outcomes in this course, we adopted many of the active learning strategies advocated by McClanahan and McClanahan (2002). These included reducing the lecture content, having the students actively seek information in the workshops instead of relying on a tutor to present material, facilitating interactions with staff able to provide feedback and encouragement to the students, and setting exam questions that required application of knowledge rather than rote learning. Some of these changes are acknowledged in the comments made by the students:

Tutorials very informative and interactive.

Variety of topics. Oral presentations. Interaction between teaching staff and students. Replies to emails.

Clear lecture structure.

The variety of Topics and Lectures. Presentations. Quiz structure. Web communication.

The use of computers for Internet access during the workshops shifted the focus from a tutor trying to generate discussion, to student-centred learning. The students were given general training in skills such as performing meaningful electronic searches, which were then used on topics that we designed to be relevant and authentic. The majority of students agreed that the workshop topics were interesting and relevant to their courses (Figure 4), thus fulfilling two criteria that are known to help people to learn (Dearn, 1997). By choosing current topics, students had to use up to date reference material. This requirement effectively exposed them to useful search methodologies and to scientific literature of immediate relevance to their courses. The student team presentations were endorsed by the students as activities that they enjoyed, which helped them learn, and which contributed to a significant improvement in their confidence at giving oral presentations.

Apart from producing good learning outcomes within this first year course, it is expected that the positive experiences in this course will encourage students to take a multidisciplinary approach to study and use the generic skills of communication and teamwork in future courses and careers.

\section{References}

Dearn, J. (1997). Teaching and the new technology: A pedagogical viewpoint. UniServe Australia Proceedings of Workshop July 15-16, The University of Newcastle, 2-6. [verified 13 Oct 2010] http: / / sydney.edu.au/science/uniserve_science/pubs/procs/ picture.pdf

Lee, S. E. \& Woods, K. J. (2010). Enhancing learning, generic skills and camaraderie through student presentations. Proceedings of the International Technology, Education and Development Conference (INTED 2010), Barcelona, Spain, 8-10 March.

Lim, K. F. \& Lee, J. (2000). IT skills of university undergraduate students enrolled in a first year unit. Australian Journal of Educational Technology, 16(3), 215-238. http: / / www.ascilite.org.au/ajet/ajet16/lim.html

McClanahan, E. B. \& McClanahan, L. L. (2002). Active learning in a non-majors biology class: Lessons learned. College Teaching, 50(3), 92-96. 
McLoughlin, C. \& Taji, A. (Eds.) (2005). Teaching in the sciences: Learner-centered approaches. Food Products Press, an Imprint of The Haworth Press, Inc. New York, London, Oxford.

Oitzinger, J. H. \& Kallgren, D. C. (2004). Integrating modern times through student team presentations: A case study on interdisciplinary team teaching and learning. College Teaching, 52(2), 64-68. http:/ / www.jstor.org/pss / 27559181

Peat, M., Franklin, S., Lewis, A. \& Sims, R. (2002). Learning human biology: Student views on the usefulness of IT materials in an integrated curriculum. Australian Journal of Educational Technology, 18(2), 255-274. http:/ / www.ascilite.org.au/ajet/ajet18/ peat.html

Pepper, C. (2009). Problem based learning in science. Issues in Educational Research, 19(2), 128-141. http: / / www.iier.org.au/iier19/ pepper.html

Zekeri, A. A. (2004). College curriculum competencies and skills former students found essential to their careers. College Student Journal, 38(3), 412-422.

Susan E. Lee and Kyra J. Woods, School of Biomolecular and Physical Sciences, Griffith University, Kessels Road, Nathan Qld 4111, Australia.

Email: s.lee@griffith.edu.au 